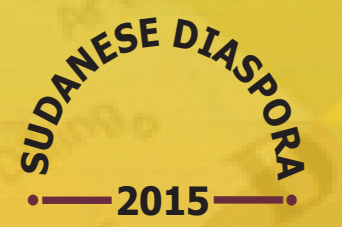

\title{
ENGAGING DIASPORA IN PROMOTING MEDICAL SPECIALTY TRAINING IN SUDAN: A PROPOSED MODEL
}

\author{
Elsheikh Badr, ${ }^{*}$ Fayrouz Abdalla and Ayat Abuagla \\ Sudan Medical Specialization Board, \\ Gasr Avenue, Old Khartoum Teaching Hospital Building, \\ P.O.Box 12892, Khartoum, Sudan \\ E-mail: elsheikh941@gmail.com \\ E-mail: Fayrouz.abdalla@gmail.com \\ E-mail:ayat.abuagla@yahoo.co.uk
}

\section{ABSTRACT}

Purpose: The Sudan Medical Specialization Board (SMSB), established in 1995, graduated over 3000 medical specialists and is currently enrolling over 4000 residents across 33 different specialty disciplines. The SMSB is currently witnessing reform characterised by role differentiation, decentralisation of training and expansion of capacity to respond to healthcare needs in Sudan and beyond. The aim of this program is to promote and institutionalise Diaspora engagement to support the specialty training and reform within the SMSB.

Approach: The SMSB is proposing a Diaspora Engagement Model (DEM) based on three streams: supporting discipline-oriented training, helping with cross-cutting generic training and enhancing institutional capacity of the board. The program involves identifying gaps and areas of needs in Sudan, developing an inventory of relevant Sudanese diaspora and implementing and monitoring the DEM. 


\section{E. Badr, F. Abdalla and A. Abuagla}

Implications and value: Engagement of diaspora is expected to address numerical and quality gaps in specialty training and impart lasting capacities that lead to sustainability. Positive return is expected in terms of health workforce development, health system strengthening and population health improvement.

Keywords: Diaspora Engagement Model; DEM; health professionals; migration; specialty training; Sudan.

\section{INTRODUCTION}

The Sudan Medical Specialisation Board (SMSB) was established in 1995 and mandated since to lead and deliver postgraduate medical specialisation programs in the country. A presidential decree in the year 2000 stipulated that the SMSB be the sole body to govern medical specialties in the country. The SMSB graduated over 3000 medical specialists since its establishment, and is currently enrolling over 4000 residents across 33 different specialty disciplines including medicine, surgery, pediatrics, obstetrics and gynecology, in addition to other relevant specialties. Currently, there are over 1200 trainers collaborating with the Board and involved in supervising resident doctors who rotate among accredited hospitals and training sites across the country.

The SMSB is currently witnessing reform characterised by role differentiation, decentralisation of training and expansion of capacity to respond to health care needs in Sudan and beyond. The SMSB governing body approved the proposed strategic shift from providing training to governing and accrediting training programs; consequent tothis, the Board started to implement a policy on introducing training centres (a group of accredited hospitals managed collectively and having control on residents' rotation) to decentralise delivery and monitoring of training activities. The Board took an important step to expand medical specialties and to introduce specialty training programs for nurses and allied health personnel, moving from medical to broader health training.

The SMSB strategy document, which is currently under development, identified several bottle necks and challenges facing the institutional reform and expansion of the specialty programs within the Board. In addition to limitations on the organisational capacity, there are challenges relating to adequacy of training sites, financial resources and the training environment. Staff instability and shortage of trainers, especially in certain critical disciplines, is one daunting challenge with consequences on production capacity and quality of training.

The strategy document proposes a range of interventions to create conditions for success of the SMSB reform. Some of the strategic directions focus on aspects pertinent to strengthening the institutional and training capacity. One proposed intervention speaks on tapping the diaspora resource to support delivery and quality of training programs; hence this initiative on systematically engaging expatriate Sudanese professionals. 


\section{PURPOSE OF THE PROGRAM}

This diaspora engagement program comes as a translation of the stipulations of the SMSB strategy in this domain.The aim of this program is to utilise the available expertise of migrant Sudanese professionals in diaspora to support the specialty training and reform within the SMSB in a sustainable manner. The idea is to provide appropriate, practical and sustainable options to improve the coverage and quality of health professionals' training in the field of medicine and health sciences in Sudan. The program will specifically focus on establishing and maintaining mechanisms and processes to enable Sudanese professionals working abroad to engage, in the form of short term contribution, in delivery of specialty training, supporting residents and trainers and enhancing the institutional capacity of the SMSB.

\section{THE COUNTRY LANDSCAPE AND RELEVANT EXPERIENCES}

In migration terms, Sudan is classified as a source country with established emigration of health professionals among other categories of skilled and non-skilled labour. It is estimated that over half of the Sudanese medical doctors (nearly 13.000) practice abroad and migration trends have been on the rise for both doctors and other health professions (Badr, 2011). The last period witnessed massive trends of emigration among the health workforce and this has been reflected in the demand for experience certificates normally sought for the purposes of working abroad. The responsible office in the Federal Ministry of Health issued over 15532 certificates in 2013 compared to 1249 in the year 2000 (FMOH, 2014). With the changing social and economic context in the country, migration of Sudanese health professionals is taking new shape with more involvement of females and the wider health professions.

The UK and the Republic of Ireland were traditionally the main destination countries for Sudanese health professionals for reasons related to colonial ties and pursue of postgraduate studies. However, the Gulf area, especially Saudi Arabia, is becoming an increasingly favoured destination for huge numbers of doctors and health professionals, probably due to geographic proximity, attractive salaries and linguistic ties. The advent of agencies adopting active recruitment is contributing to the strong pull towards labour markets in the Gulf and Saudi Arabia. Some recent studies demonstrate that low remuneration, lack of adequate training opportunities and poor work environment are the leading push factors for emigration in Sudan (Abuagla, 2013).

Implications of the massive emigration of health professionals are clearly felt in the Sudanese health system. Coverage of healthcare suffers due to internal migration of staff moving to big cities and urban areas to replace those leaving to work abroad. In its quest for universal health coverage, Sudan is left with over $14 \%$ of its population lacking access to essential health care (Badr et al., 2013). In addition, quality of health services also suffers due to loss of qualified staff, especially in some disciplines where the critical mass was not already 


\section{E. Badr, F. Abdalla and A. Abuagla}

in place. Additionally, migration is affecting the capacity of health professions education in the country. Loss of qualified staff in the basic sciences and clinical disciplines is jeopardising sustainability and quality of educational programs at both basic and post-graduate levels. The University of Khartoum is estimated to have lost $40 \%$ of its staff to outmigration (Eltahir, 2015). The loss of qualified university staff in the medical disciplines has adverse ramifications on the medical specialty training within the SMSB as those teachers are traditionally part of the mass of trainers for the Board. In some critical specialties such as oncology and neurosurgery, the SMSB is graduating less than 10 candidates per year due mainly to limitations on the number of trainers.

Engaging expatriate professionals in the development of their own home countries, through short visits and assignments, has been tried in many places. Tapping on the diaspora resource is a strategic direction in managing professional migration facilitated by many international organisations and development partners such as the International Organisation for Migration (IOM), the World Health Organization (WHO) and the United Nations Development Program (UNDP). Migration for Development in Africa (MIDA) is a successful initiative organised by the IOM and it is aimed at mobilising diaspora to engage in supporting development and services back in their home countries. The Ghana/Netherlands program is often quoted as example of successful collaboration in this respect (IOM, 2003). Transfer of Knowledge through Expatriate Nationals (TOKTEN) is another initiative by the UNDP with the aim to promote volunteerism among diaspora to contribute to development and to reverse the effects of brain drain. The World Health Assembly adopted in 2010, a global code of practice on migration calling for mobilising diaspora contribution to home countries among other interventions |(WHO, 2010).

The Sudanese diaspora is described to be rich in expertise, vivid and highly willing to contribute to in-country programs and activities (Badr, 2005). The record of diaspora contribution and initiatives in the health and education domains, for instance, stands out as testimony for the potential and willingness of expatriate Sudanese health professionals to give back to home country. In the medical field, the Sudanese diaspora organises itself in forms of active groups, associations and networks as seen in some main destination countries especially in the West and as demonstrated by the web-based virtual networks. Many Sudanese expatriates' initiatives have been documented whether through collective or individual efforts, and most of these contributions imparted essential capacity in support of healthcare (FMOH, 2011).

Despite a vivid Sudanese diaspora and some positive returns in terms of technical capacity and remittances, there are some constraints and challenges facing the full utilisation of the diaspora potential. Barriers for maximising diaspora contribution in the health sector were described to be relating to lack of robust planning, effective communication and poor coordination from the side of country entities (Abdalla, 2013). These bottlenecks are also reflected in experiences elsewhere, especially with regards to the lack of effective coordination among relevant government agencies (IMO, 2005). The comprehensive 


\section{Engaging diaspora in promoting medical specialty training in Sudan}

framework and logistical arrangements to makethe environment conducive to streamlining and rationalising diaspora contribution are often not fully in place. This program, through appropriate coordination mechanisms using the promising capacity of the SMSB, aims to provide appropriate, practical and sustainable options to improve the coverage and quality of medical specialty training in Sudan through diaspora engagement. The program hypothesis is based on the premise that the expatriate Sudanese health professionals should be seen as integral to the collective human capacity available to support health development in Sudan.

\section{THE PROPOSED APPROACH}

The SMSB is proposing a Diaspora Engagement Model (DEM) to support specialty training in Sudan. The model is based on three related streams (Figure1): covering specific contribution to specialty training, supporting the cross-cutting training for generic skills, and helping with the enhancement of the institutional capacity of the Board.

In the domain of supporting specialty training, diaspora contribution can take several forms such as delivering lectures, providing short skills-oriented training and supervising and guiding trainees. Sudanese specialists and senior consultants in diaspora can effectively add to the examining mass of the SMSB, especially in the capacity of external examiners and assessors. They can also play pivotal role in linking residents and trainees to learning

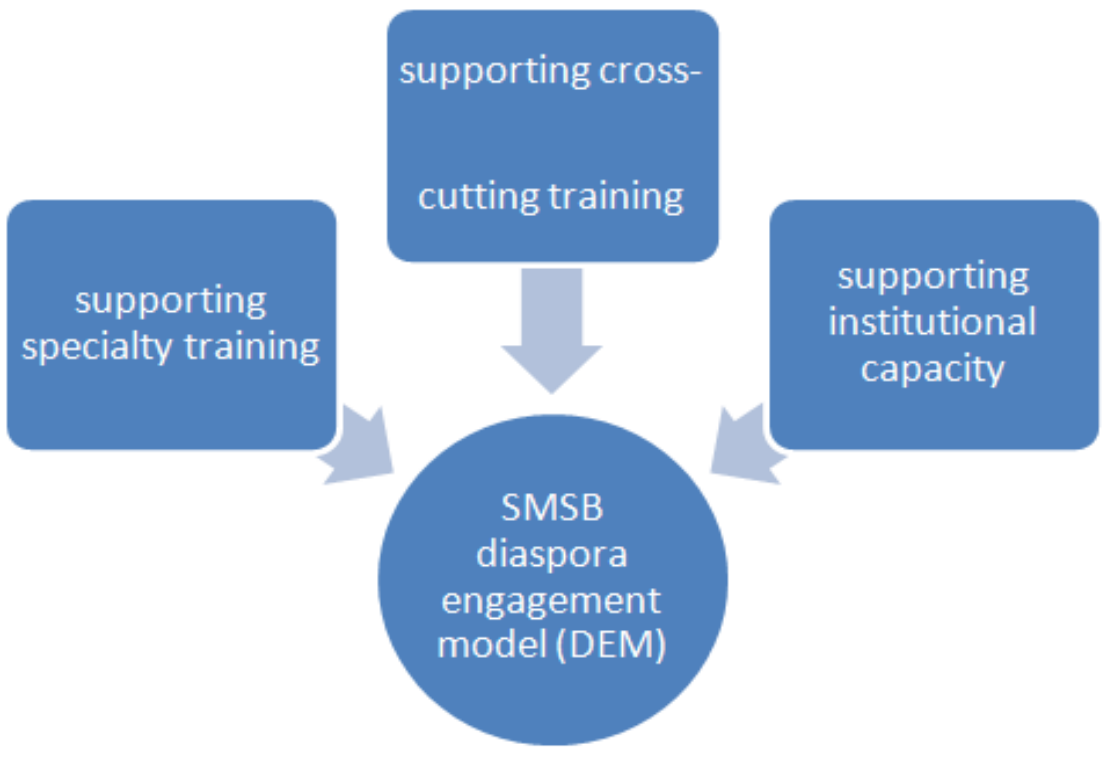

Figure 1 Areas of possible diaspora engagement to support the mission and functions of the SMSB 


\section{E. Badr, F. Abdalla and A. Abuagla}

resources and overseas training opportunities. Through their collective power as groups and associations, health professionals in diaspora can impart critical knowledge, skills and competencies through organising conferences, meetings and workshops in collaboration with the specialty councils within the SMSB. This type of activity has been shown to be useful and in demand by both trainers and trainees in Sudan.

As for the cross-cutting training, the expertise of diaspora professionals is certainly needed to promote delivery of a range of generic training courses aimed at inculcating professional, research and broader skills necessary to graduate a 'fit for purpose' and'fit to practice' health workforce. Support of the capacity of trainers in this area is going to be an additional benefit based on the identified needs for staff development. With the expansion of the SMSB programs to involve other health professions in addition to medicine, the need for collective training and orientation is pertinent and diaspora contribution in this area could be useful to strengthen inter-professional education and eventually inter-professional practice.

In the domain of institutional capacity, a wide range of diaspora contribution would be pertinent in different areas of expertise and potential within and beyond the medical field. Professionals with expertise in planning, development, business and economics are seen as critical resource to support strategic planning, business strategy and organisational setup for the SMSB. Other areas for engagement include educational development covering functions such as curriculum development, educational quality, assessment and educational reform. Support for the information technology, research and knowledge management is also a pivotal domain for diaspora engagement. Through their individual and collective networking, professionals in diaspora can promote and strengthen collaboration arrangements of the SMSB with similar and related agencies in countries of destination.

Bringing together the three streams of possible diaspora contribution into one program, the DEM proposed by the SMSB could broaden the base and provide the necessary platform to enable involvement of a wide range of expertise and thus strivetowards utilising the full potential of the Sudanese working abroad. The model shall learn in this respect from

\section{Box 1 The salient features of the DEM proposed by the SMSB}

- Comprehensive in coverage, addressing capacity in a holistic approach

- Based on needs/gaps and demand driven

- Clearly defined outcomes and results

- Inclusive and participative in nature

- Goes beyond medical and health expertise

- Observes the need for sustainability and strategic focus

- Grounded in reality and informed by previous experiences 
experiences of diaspora contribution in different aspects in Sudan and beyond. Given the observation that diaspora engagement is often ad hoc in nature and lacks appropriate frameworks to mainstream contributions into institution building and development (African Development Bank, 2011), this DEM could add to knowledge and provide lessons for effective integration of expatriates' potential into home country needs and programs in a systematic and sustainable manner. The following box summarises the salient features of the DEM proposed by the SMSB.

\section{IMPLEMENTATION OF THE DEM}

The implementation modality for the program shall be systematic, emphasising the logical sequence of steps leading to attaining the desirable deliverables and outcome of Diaspora engagement. The SMSB is contemplating on establishing a program management unit with competent staff and focal persons in order to oversee and monitor the implementation of the DEM. The following are the basic steps required to implement the model.

\section{IDENTIFICATION OF NEEDS/GAPS}

The SMSB shall discus and consolidate its needs, identify gaps, and stipulate relevant areas for diaspora contribution. This process shall be guided by the three streams of work included in the DEM: specialty specific training, cross-cutting training and institutional capacity. In each area, relevant entities within the SMSB are going to contribute and distill their ideas and views in an effort to reach a demand-driven agenda for diaspora contribution. The consolidated needs/gaps shall be shared and communicated beyond the SMSB for review and congruence before being endorsed. There will be a mechanism to update the exercise on needs and gaps as relevant in order to respond to emerging needs and to keep up with new developments.

\section{DEFINITION OF THE MODEL OF ENGAGEMENT}

The proposed DEM introduced in this paper shall form the basis for integrating and streamlining contributions from the Sudanese diaspora. As explained earlier, this model provides opportunities and a platform to absorb and assimilate different talents from subjectspecific to broader generic and capacity expertise. There will be further delineation of the proposed DEM to create a common understanding and set detailed agenda with diaspora groups and individuals. 


\section{DETERMINING DIASPORA POTENTIAL}

This step is critical in order to match the identified needs and gaps within the SMSB to the relevant expertise and competencies available among diaspora members. Despite the existence of several diaspora networks and groups, evidence on the number and expertise of Sudanese expatriate professionals has always been inadequate (Abdalla, 2013). This program is going to adopt a multidimensional approach to create and maintain an inventory on the relevant diaspora resource. This inventory shall benefit from existing information resources, communication with relevant entities and the information technology potential. The SMSB is introducing a web-based platform to enable creation of an electronic database on diaspora professionals deemed suitable to engage in supporting specialty training in Sudan. The response and cooperation from the side of expatriate professionals is fundamental to the success of this endeavour.

\section{MONITORING AND EVALUATION}

While the diaspora potential and expertise is matched to the identified needs in terms of actual implementation of activities based on the DEM, a framework and mechanism for monitoring shall be put in place in order to keep track of the process and guide any corrective action.

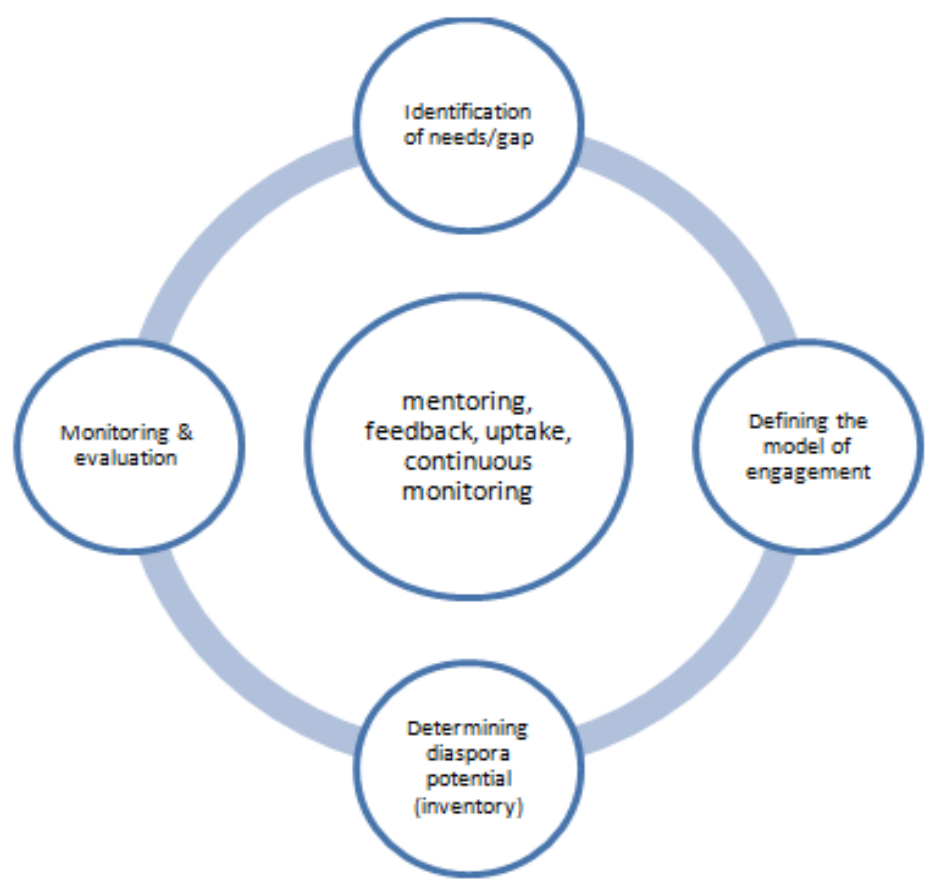

Figure 2 The implementation cycle pertaining to engaging diaspora to support specialty training in Sudan 
The SMSB shall also ensure the necessary arrangements for formative and summative evaluation to generate evidence on the program achievements and to inform future improvements. To ensure functionality and enrich the implementation process, oversight and continuous feedback is going to be observed throughout the cycle of the implementation. Figure 2 below depicts the implementation process for the DEM proposed by the SMSB.

For reasons related to ensuring effective implementation, institutionalisation and sustainability of the DEM; the SMSB is planning to adopt an action research approach to managing and implementing this initiative. The program management unit supported by suitable expertise shall constitute the action research team. In addition to contributing to quality implementation and sustainability, the action research approach is also expected to impart capacity and learning for other initiatives within the SMSB and beyond.

\section{IMPLICATIONS, VALUE AND IMPACT}

Successful implementation of the proposed DEM is expected to add value and bring in several benefits both on the side of the country and the diaspora. The SMSB expects tangible implications and contributions to the coverage and quality of specialty training programs through making use of the critical expertise available among expatriate professionals. Knowledge and technology transfer, in addition to mobilisation of technical support and useful links, are all expected benefits to capacity strengthening within the SMSB and beyond. In the medium to long-term, impact on improvement of healthcare and health indicators should also be felt. On the side of diaspora, the DEM is going to be a unique platform to realise the ambitions, will and passion of the expatriate professionals to contribute to their own people and community. In addition to satisfaction and content, the diaspora members are also expected to benefit professionally and in terms of future planning from their sustained interaction with colleagues and institutions in the country.

\section{REFERENCES}

Abdalla, F. (2013) Sudanese Medical Diaspora: Options for Contribution to the Health Care Delivery System in Sudan, MD thesis, Sudan Medical Specialization Board.

Abuagla, A. (2013) Magnitude, Trends and Implications of Health Professional Out-Migration in Sudan 2012, Khartoum, MD thesis, Sudan Medical Specialization Board.

African Development Bank (2011) The Role of Diaspora in Nation Building: Lessons for Fragile and PostConflict Countries in Africa, Available at: http://www.afdb.org/fileadmin/uploads/afdb/Documents/ Project-and-Operations/2011\%20The\%20role\%20of\%20the\%20Diaspora\%20in\%20Nation\%20 building\%20-\%20lessons\%20for\%20fragile\%20and\%20post-\%20conflict\%20countries\%20in\%20 Africa.pdf, Accessed on 2 May 2015. 


\section{E. Badr, F. Abdalla and A. Abuagla}

Badr, E. (2005) Brain Drain of Health Professionals in Sudan: Magnitude, Challenges and Prospects for Solution, MA thesis, University of Leeds, UK.

Badr, E. (2011) 'Migration of health professionals in Sudan: need for a national policy? 'Sudanese Journal of Public Health, Vol. 6, No. 3, p.75.

Badr, E., Mohamed, N., Afzal, M. and Bile, K. (2013) 'Strengthening human resources for health through information, coordination and accountability mechanisms: the case of the Sudan', Bulletin of the World Health Organization, Vol. 91, pp.868-873.

Eltahir, A. (2015) The Challenge of Migration Among Higher Education Staff, Presentation to the annual University of Khartoum Alumni meeting, Khartoum, 14 January 2015.

Federal Ministry Of Health-FMOH (2011) The National 5 years Strategic Plan for Human Resources for Health (2011-2016), Khartoum, FMOH.

Federal Ministry of Health-FMOH (2014) Report of the Experience Certificates Office for the Year 2013, Human Resource Department, FMOH.

International Organization for Migration-IOM (2003) World Migration Report. Managing Migration: Challenges and Responses for People on the Move, IOM, Geneva.

International Organization for Migration-IOM (2005) 'Results of the Survey engaging diasporas as agents for development', Available at: https://www.iom.int/jahia/webdav/site/myjahiasite/shared/ shared/mainsite/policy_and_research/research/Diaspora\%20questionnaire\%20analysis.pdf, Accessed on 3 May 2015.

World Health Organization (2010) The Global Code of Practice on the International Recruitment of Health personnel, Available at: http://www.who.int/hrh/migration/code/WHO_global_code_of_practice_ EN.pdf, Accessed on 28 April 2015.

\section{BIOGRAPHICAL NOTES}

Elsheikh Badr is a consultant public health physician with expertise in health system and human resource development. He gained his basic medical degree and post-graduate public health diploma and fellowship in community medicine from Sudan; his masters degree in health policy, planning and management from the University of Leeds in addition to the fellowship of the Faculty of Public Health of the Royal Colleges of Physicians in the UK. Currently, he serves as the Secretary General for the SMSB, the prime post-graduate medical education body in Sudan. Prior to this, he served for over 15 years in the Federal Ministry of Health in senior positions including director of the Department of Human Resources for Health Development, founding director of the National Human Resources for Health Observatory and President of the Academy of Health Sciences. Academic and professionals contributions of his varied including teaching and supervising at both undergraduate and postgraduate medical education, serving as founding Editor of the Sudanese Journal of Public Health, and publishing and presenting at over 25 international conferences and meetings. He served as WHO health workforce consultant several times and worked with WHO EMRO on the regional health workforce strategy and other aspects. He has been part of a number of global initiatives/taskforces with WHO, Global Health Workforce Alliance (GHWA) and other entities. Notable contributions include serving as member of the Global Health Worker Migration Policy Council since 2007, member of the global taskforce on monitoring implementation of Kampala Declaration, and Co-chair of the global 
thematic working group on health workforce issues in fragile/conflict affected states. He was recently appointed to membership of the WHO global Expert Advisory Group (EAG) on reviewing the relevance and effectiveness of the WHO Global Code of Practice on the International Recruitment of Health Personnel.

Fayrouz Abdalla is a medical doctor with experience in health system, public health and community medicine. Her expertise is in the areas of, human resources development including planning and policy, training and teaching, health management information system, disaster management and health systems research. She has a post-graduate diploma degree in research methods and biostatistics from the University of Medical Sciences and Technology in Sudan, a master's degree in health management, planning and policy from the University of Leeds in UK and an MD in community medicine from the SMSB. Currently, she is holding a title of an Assistant Professor of community medicine in the School of Health Sciences, Ahfad University for Women in Sudan. She teaches different courses in public health and health management to undergraduate and post-graduate student and supervises researches. Besides her work at Ahfad, she has joined the SMSB and is appointed as the focal person for the diaspora engagement program at the SMSB. She is providing technical assistance and consultancies to many health institutions in Sudan. She has worked with the Sudan's National Health Insurance Fund in 2013 as a consultant to conduct training needs assessment. She worked as a manager in different departments of the Human Resources for Health General Directorate in Sudan, where she was involved in training needs assessment and the development of tailor made courses for different groups using innovative teaching methods. Prior to that, she worked in the Emergency and Humanitarian Action directorate of the Directorate General of the International Health, where she was actively involved in emergency planning and response activities in many flood prone states in Sudan and in the development of flood disaster management training materials and staff training in centre and states. As part of her MD degree, she has conducted a major health system research on Sudanese medical diaspora and the options for their contribution to the healthcare delivery system in Sudan.

Ayat Abuagla Public Health Physician; Reproductive health and Health system expert. She has diverse work experience through positions in healthcare, academia and professional associations. She assumed positions in the Federal Ministry of Health including: Head of Research and Publications at the National Human Resources for Health Observatory (NHRHO), Monitoring and Evaluation Officer, Quality Directorate officer of the HR Development Directorate. Currently, she is involved in the SMSB at the International Relations office of the EDC centre. During her career she has been actively engaged in public health, reproductive health and health systems work at national, regional and global spheres. She travelled widely and attended several events and presented at several conferences on reproductive health and health system topics. She served as TDR/WHO Implementation Research advisor several times since piloting of the toolkit till present. Contribution related to reproductive health include: Co-founder of Rebuilding Reproductive and Child Health System in Post Conflict Settings' Initiative (ReReCHI); Leading investigator of the Innovative Participatory Health Education (IPHE) One of the Top 10 Educational Initiatives and Solutions Improving the Life of Girls and Women Worldwide by Women Deliver. She contributed to revival and strategic shift and focus on Human Resources for Health (HRH), these include: Leading investigator First Mapping of health and medical education pipeline survey; Principle Investigator of the Health Labour Market Study with WHO-HQ/EMRO/AFRO; Produced a 
medical doctorate thesis in 2013 titled: Magnitude, Trends and Implications of Health Professional Out Migration in Sudan, 2012. As a result of the two year research; a series of forums were conducted; dissemination meetings and round table all paving the way for the first milestone of a Migration Management Policy she is leading. Actively involved in advocacy for addressing health system and HRH challenges and Health worker migration in Sudan through organising meetings and participating in workshops and forums. 